\title{
Direct-bonded aluminum on aluminum nitride substrates by transient liquid phase bonding
}

\author{
Yoshirou KUROMITSU ${ }^{\dagger}$, Yoshiyuki NAGATOMO, Kazuhiro AKIYAMA, \\ Naoya SHIBATA* and Yuichi IKUHARA* \\ Central Research Institute, Mitsubishi Materials Corp., Naka, Ibaraki 311-0102, Japan \\ *Institute of Engineering Innovation, The University of Tokyo, Tokyo 113-8656, Japan
}

\begin{abstract}
A new bonding process has been developed for producing direct-bonded aluminum (DBA) substrates using aluminum nitride (AIN). A transient eutectic liquid phase forms in aluminum-X $(X=$ silicon, germanium, silver, or copper $)$ systems at the interface between the aluminum foil and the AIN substrate. The aluminum-X liquid phase transiently contacts the AlN substrate prior to isothermal solidification by diffusion of the element $X$ into the aluminum foil. We have prepared DBA substrates using this process and demonstrated that they are highly stable after thermal cycling testing.
\end{abstract}

(2017 The Ceramic Society of Japan. All rights reserved.

Key-words : Aluminum Nitride, DBA (Direct Bonded Aluminum) substrates, TLP (Transient Liquid Phase) bonding

[Received October 24, 2016; Accepted January 4, 2017]

\section{Introduction}

Direct-bonded copper (DBC) substrates have been widely used in general power electronics for many years. Aluminum nitride (AIN) has been used as a ceramic for DBC substrates, especially for extracting heat from silicon chips, because of its high thermal conductivity.

Direct-bonded aluminum (DBA) substrates using AlN have been developed to replace DBC substrates and have also been practically used in insulated gate bipolar transistor (IGBT) modules for hybrid electric vehicles, which require very high reliability under conditions of severe thermal stress. ${ }^{1), 2)}$

Finite element method (FEM) analysis has revealed that the superior reliability of DBA substrates over DBC substrates under high thermal stress conditions is due to the different plastic deformation behaviors of aluminum and copper. ${ }^{3)}$

Two different methods are employed to bond aluminum to AIN substrates in practical applications. One involves inserting a brazing film between the aluminum and the AlN substrate and then melting the brazing film. ${ }^{1)}$ The other involves melting aluminum directly on AIN substrates without using a brazing film. ${ }^{4)}$

In this study, a new process was developed for bonding aluminum with AlN that uses a transient liquid phase (TLP). DBA substrates were fabricated by this new method and their properties were evaluated.

\section{Experimental procedures}

\subsection{DBA substrates}

We first deposited element $\mathrm{X}(\mathrm{X}=$ silicon, germanium, silver, or copper) on a high-purity ( $>99.99 \%$ ) aluminum foil by electronbeam evaporation. Elements $\mathrm{X}$ that lower the melting point of aluminum were selected based on phase diagrams considering the TLP concept. ${ }^{5)}$ The thicknesses of the element $X$ layers were determined such that they produce the same amount $(=10 \mu \mathrm{m})$ of the eutectic liquid phase at the aluminum/AIN interfaces. The

\footnotetext{
Corresponding author: Y. Kuromitsu; E-mail: y-kuro@mmc.co.jp
}

thicknesses of the silicon, germanium, silver, and copper layers were $1.4,3.5,4.2$, and $1.3 \mu \mathrm{m}$, respectively.

We then produced layered samples (= DBA substrates) in which a commercially available well-sintered AlN substrate was sandwiched between two X-deposited films. Specifically, these DBA substrates had the following structures: X-deposited aluminum foil/AlN substrate/X-deposited aluminum foil. Each DBA substrate was heated at a temperature above the Al-X eutectic point for $30 \mathrm{~min}$ in a vacuum under a pressure of $0.4 \mathrm{~N} / \mathrm{mm}^{2}$.

\subsection{Model samples}

We also prepared two model samples $(\mathrm{X}=\mathrm{Si})$ for transmission electron microscopy (TEM) observations and energy-dispersive $\mathrm{X}$-ray spectroscopy (EDS) analysis in order to understand the interfacial microstructure between aluminium and AIN substrate. The structure and the preparation method of these two model samples are basically the same as the above DBA substrates except for the AlN substrate. We used single crystalline AIN substrate which is commercially available epitaxial AlN films on a sapphire. $\left.{ }^{6}\right)$ Here, one model sample was heated at $650^{\circ} \mathrm{C}$, and the other sample was heated at $600^{\circ} \mathrm{C}$.

\section{Results and discussion}

Figure 1 schematically illustrates the above new bonding process for producing DBA substrates. A transient eutectic liquid phase forms in Al-X systems at the aluminum/AlN interface. The Al-X liquid phase transiently contacts the AlN substrate before isothermal solidification occurs by element $\mathrm{X}$ diffusing into the aluminum foil.

The reliability of these DBA substrates was evaluated by thermal cycling testing $\left(1000\right.$ cycles between -40 and $150^{\circ} \mathrm{C}$ in air). In our previous paper, ${ }^{7)}$ fracturing of the aluminium/AlN interface with thermal cycling was assessed by observing changes in the aluminium/AlN interface using an ultrasonic flaw detector. In this study, the same method using an ultrasonic flaw detector was applied to each DBA substrate.

Figure 2 shows the effect of element $X$ and heating temperature on the reliability of the DBA substrates. In the heating 


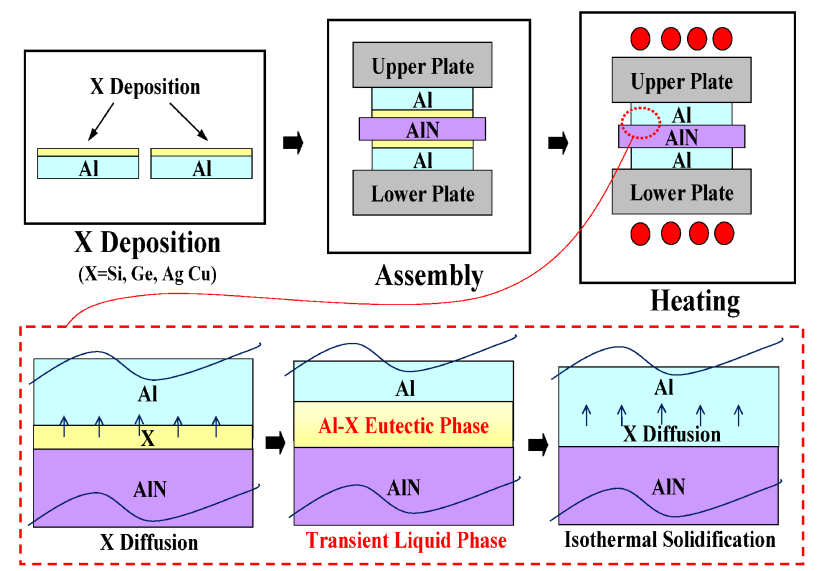

Fig. 1. New bonding process for producing DBA substrates by transient liquid phase (TLP) bonding.

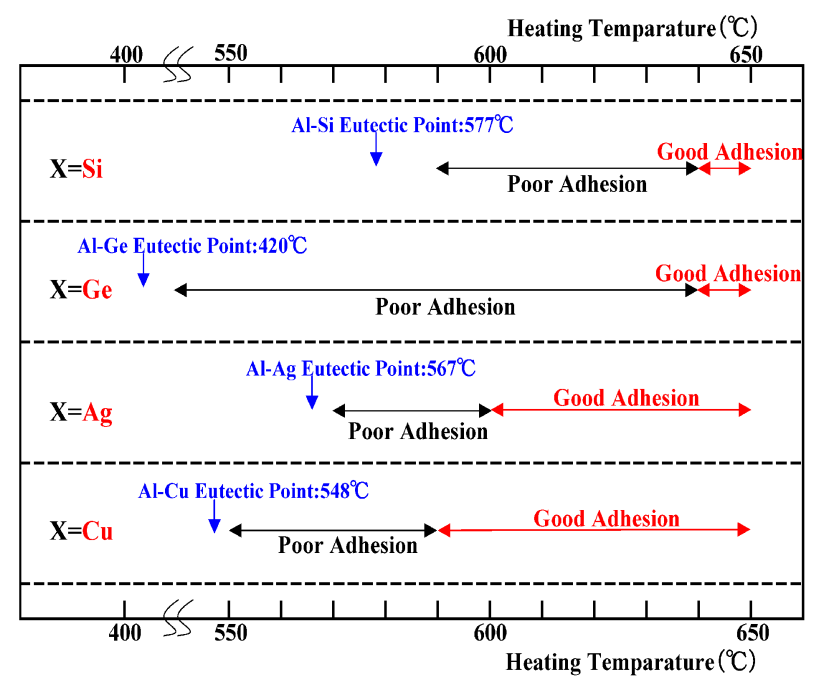

Fig. 2. Effect of element $\mathrm{X}$ and heating temperature on the adhesion reliability of DBA substrates.

temperature range designated as good adhesion, the DBA substrates were highly stable and did not exhibit any fracture propagation detected by using an ultrasonic flaw detector after thermal cycling testing. On the other hand, in the heating temperature range designated as poor adhesion, the DBA substrates had fractures detected by using an ultrasonic flaw detector at the aluminium/AlN interfaces after thermal cycling testing. The temperature range at which good adhesion occurred depended on element X. Based on these results, the different temperature ranges of good adhesion for the $\mathrm{Al}-\mathrm{X}$ eutectic systems are considered to be controlled by the different reactivities between the Al-X eutectic liquid and AlN.

Figure 3 and 4 show TEM images for the interface between aluminum and the single crystalline AlN in the model samples $\left(\mathrm{X}=\mathrm{Si}\right.$ ) after heating 650 and $600^{\circ} \mathrm{C}$, respectively. Table $\mathbf{1}$ and $\mathbf{2}$ show the results of EDS analysis for designated areas in Figs. 3 and 4, respectively. From these TEM observations and EDS analysis, the $650^{\circ} \mathrm{C}$ heating sample had a heterointerface between aluminium and $\mathrm{AlN}$, with no interfacial specific layer. And although most silicon as element $\mathrm{X}$ diffused into the aluminum, a certain amount of silicon segregated at the interface (area B). On the other hand, interfacial layer between aluminium and AlN as shown in Fig. 4 was clearly observed in the $600^{\circ} \mathrm{C}$ heating

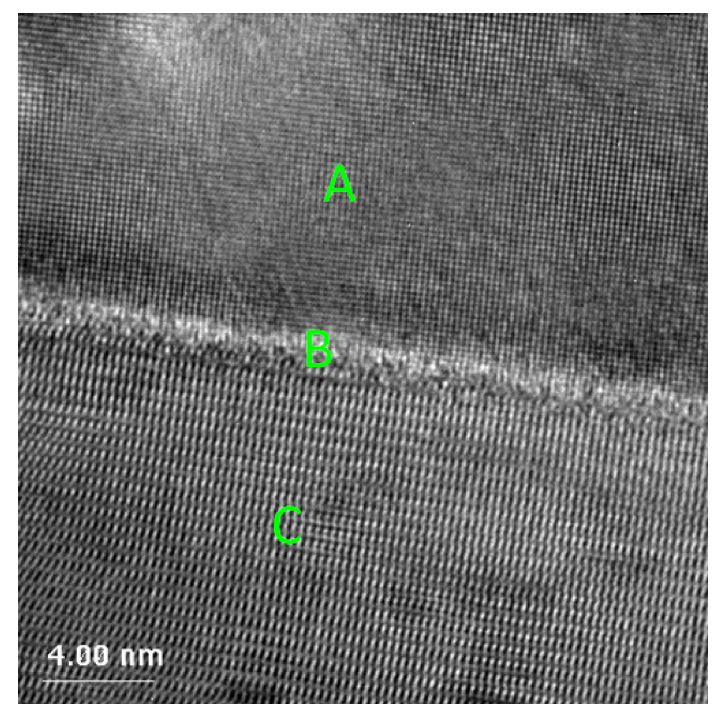

Fig. 3. TEM image of the interface between aluminium and the single crystalline $\mathrm{AlN}$ in the model sample $(\mathrm{X}=\mathrm{Si})$ after $650^{\circ} \mathrm{C}$ heating.

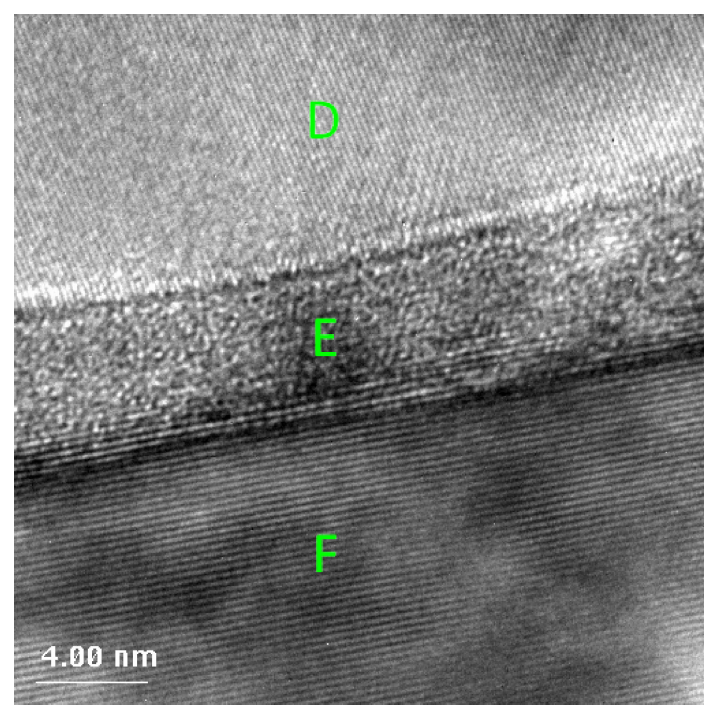

Fig. 4. TEM image of the interface between aluminium and the single crystalline $\mathrm{AlN}$ in the model sample $(\mathrm{X}=\mathrm{Si})$ after $600^{\circ} \mathrm{C}$ heating.

Table 1. Elemental composition (at \%) by EDS analysis for the areas in Fig. 3

\begin{tabular}{rrrr}
\hline & A & \multicolumn{1}{c}{ B } & \multicolumn{1}{c}{ C } \\
\hline $\mathrm{Al}$ & 90.1 & 63.9 & 45.8 \\
$\mathrm{Si}$ & 0.0 & 4.6 & 0.2 \\
$\mathrm{O}$ & 3.6 & 13.3 & 1.3 \\
$\mathrm{~N}$ & 6.3 & 18.2 & 52.7 \\
\hline
\end{tabular}

Table 2. Elemental composition (at \%) by EDS analysis for the areas in Fig. 4

\begin{tabular}{crrr}
\hline & $\mathrm{D}$ & $\mathrm{E}$ & \multicolumn{1}{c}{$\mathrm{F}$} \\
\hline $\mathrm{Al}$ & 90.0 & 39.5 & 48.8 \\
$\mathrm{Si}$ & 0.0 & 0.2 & 0.0 \\
$\mathrm{O}$ & 4.0 & 34.6 & 0.7 \\
$\mathrm{~N}$ & 6.0 & 25.7 & 50.5 \\
\hline
\end{tabular}


sample. However, silicon mostly was not detected inside the interfacial layer between aluminium and AlN.

As shown in Fig. 2, the DBA substrate $(\mathrm{X}=\mathrm{Si})$ after heating $650^{\circ} \mathrm{C}$ showed good reliability in terms of the adhesion between aluminium and AlN. On the other hand, the $600^{\circ} \mathrm{C}$ heating DBA substrate had fractures at the aluminium/AIN interfaces after thermal cycling testing. These results combined with the abovementioned TEM images in Figs. 3 and 4 suggest that the interfacial layer between aluminium and AIN degrades a reliability of the aluminium/AlN adhesion.

\section{Conclusions}

A new bonding process has been developed for producing DBA substrates by TLP bonding. DBA substrates prepared by this process with suitable heating conditions were highly stable and did not exhibit any interfacial fractures after thermal cycling testing.

TEM observations for the model samples using single crystalline AlN substrates revealed that these DBA substrates had heterointerfaces between aluminium and AIN without any specific interfacial layer.

Acknowledgments We thank Mr. Hiroshi Tonomura and Dr. Christine Marie Montesa for their technical supports.

\section{References}

1) M.Toriumi, H.Tanaka and H. Yoshida, IMC 1994 Proceedings, 104-109 (1994).

2) T. Harada and Y. Baba, Proceedings of 15th International Conference of Electric Vehicles (EVS-15) (1998) CD-ROM.

3) Y. Nagatomo and T. Nagase, Proceedings of 17th International Conference of Electric Vehicles (EVS-17) (2000) CD-ROM.

4) X. S. Ning, Y. Ogawa and K. Suganuma, Proceedings of Materials Research Society Symposium, 445, 101-106 (1997).

5) A. A. Shiradi and E. R. Wallach, Mater. Sci. Technol., 13, 135142 (1997).

6) C. M. Montesa, N. Shibata, N. Tohei and Y. Ikuhara, J. Mater. Sci., 46, 4392-4396 (2011).

7) Y. Nagatomo, R. Muranaka, H. Hayashi, Y. Kuromitsu and N. Kuwano, Mater. Sci. Forum, 638-642, 3895-3900 (2010). 